\title{
Commentary: The internal thoracic artery does know or care whether you are male or female
}

\author{
George L. Hicks, MD
}

\author{
From the Division of Cardiothoracic Surgery, University of Rochester Medical Center, Rochester, NY. \\ Disclosures: Author has nothing to disclose with regard to commercial support. \\ Received for publication Jan 10, 2019; accepted for publication Jan 11, 2019; available ahead of print Feb 22, \\ 2019. \\ Address for reprints: George L. Hicks, MD, Division of Cardiothoracic Surgery, University of Rochester Medical \\ Center, 601 Elmwood Ave, Rochester, NY 14942 (E-mail: george_hicks@ urmc.rochester.edu). \\ J Thorac Cardiovasc Surg 2019;158:1354-5 \\ $0022-5223 / \$ 36.00$ \\ Copyright (c) 2019 by The American Association for Thoracic Surgery \\ https://doi.org/10.1016/j.jtcvs.2019.01.045
}

Over the past year, I have had the opportunity to opine on several papers regarding coronary revascularization using single internal thoracic artery (SITA), bilateral internal thoracic artery (BITA), or all-arterial grafting. ${ }^{1,2}$ In each of these studies, the common theme emerges that arterial grafting promotes improved long-term survival at little or no cost to the patient in terms of early postoperative complications. In this issue of the Journal, Vrancic and colleagues ${ }^{3}$ compare short- and long-term results of BITA grafting strategies based on sex followed by a subgroup analysis of women younger than 65 years old and those older than 65 years.

The paper is a single-institution, retrospective analysis of 4406 consecutive patients undergoing coronary artery bypass grafting between January 2000 and April 2017. The authors identified 2979 patients receiving BITA, of whom $299(10.1 \%)$ were women. The purpose of the study was to analyze the long-term benefit (if any) of BITA using propensity matching in both women younger than 65 years and older than 65 years. The data collected included early adverse events as well as 10-year follow-up for survival, revascularization, and stroke.

The authors present unadjusted data that demonstrated female patients receiving BITA were older $(P<.001)$, had nonelective surgery $(P<.001)$, more on-pump coronary artery bypass grafting $(P=.015)$, and fewer grafts $(P<.001)$ versus male patients receiving BITA. BITA grafting in women had an equivalent long-term survival as men in the unadjusted comparison $(P .784)$ and in adjusted analysis $(P$.382). In the unadjusted comparison, BITA women had greater postoperative mortality $(2.3 \%$ vs $1 \%, P=.048)$, greater incidence of postoperative stroke $(1.3 \%$ vs $0.3 \%$, $P<.013)$, and greater incidence of mediastinitis $(3.3 \%$ vs $1.5 \%, P<.022$ ) than men receiving BITA. However, when risk-adjusted data are used, BITA in women has the same postoperative results as men. Furthermore, among women, the use of BITA improved long-term survival (hazard ratio $0.59 ; P<.001$, including those older than 65 years ( $\mathrm{n}=131)$.

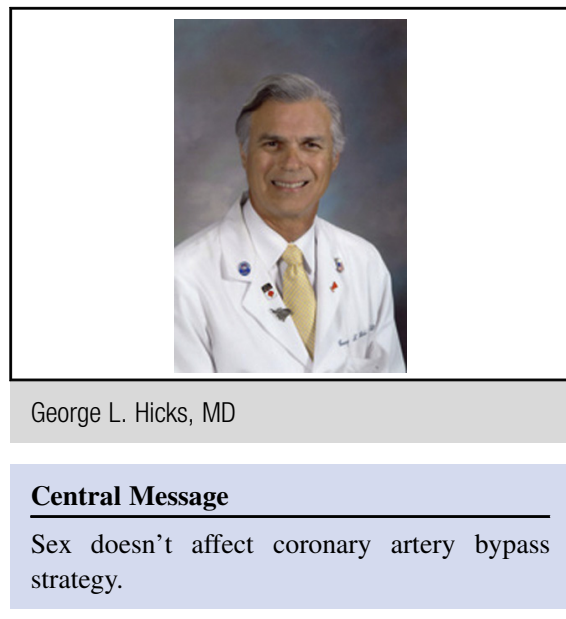

See Article page 1345 .

old who showed superior long-term survival compared with the SITA group, $P=.019$ ).

The authors have added some further evidence regarding the value of BITA in long-term survival in women. The study may have some issues with underpowering, especially in the matched groups of women with SITA versus BITA

The authors have tried in earnest to provide a statistical argument for the use of BITA in patients undergoing coronary revascularization, especially women of increasing age. They are to be congratulated for the more than $60 \%$ penetrance of BITA grafting in this group of patients, far exceeding the national norm of $5 \%$ to $10 \%$. Also the importance of emphasizing the skeletonization technique for BITA provides lower risk of sternal complications as well as additional length to improve vascularization access to most cardiac vessels.

As important as these messages are, and I believe they are important ones, the authors fail to provide the reader the critical data necessary to carry forward the adoption of BITA or perhaps all-arterial coronary revascularization to improve long-term survival in our patients, especially women. Unfortunately, the authors used a relatively arbitrary age of 65 years as the comparison of young versus old women and fail to provide the critical data regarding true risk stratification to allow a more objective measure of true risk. They give no information regarding cholesterol, 
menopausal status, body mass index, or vessel sizes, all of which play some role in early and late results.

Second, the paper does not clarify the best revascularization strategy for a given patient with objective risk stratifications whether male or female, such as when or where is it best to use a right internal thoracic artery based on vessel size, degree of proximal stenosis, and amount of territory perfused. It will be these questions that need to be answered by more robust and objective reports in the future. When such information is available, we will finally be able to provide an evidence-based approach to coronary revascularization and provide better algorithms for cardiac surgeons to optimize the usage of BITA, all-arterial, radial artery, or saphenous vein bypass grafting based not on age but objective risk assessment tools and provide our patients with the optimal survival benefit that they deserve.

\section{References}

1. Hicks GL. Are men from mars and women from Venus. J Thorac Cardiovasc Surg. 2017;153:580-1.

2. Hicks GL. Two out of three ain't bad but .... J Thorac Cardiovasc Surg. 2019;157: 2240-1.

3. Vrancic JM, Navia DO, Espinoza JC, Piccinini F, Camporrotondo M, Benzadon $\mathrm{M}$, et al. Is sex a risk factor for death in patients with bilateral internal thoracic artery grafts? J Thorac Cardiovasc Surg. 2019;158:1345-53.e1. 